Article

\title{
Two New Iridoid Glycosides from the Root Barks of Sambucus williamsii Hance
}

\section{Zhen-Yue Wang $^{\dagger}$, Hua Han ${ }^{\dagger}$, Bing-You Yang, Yong-Gang Xia and Hai-Xue Kuang *}

Key Laboratory of Chinese Materia Medica, Heilongjiang University of Chinese Medicine, Ministry of Education, Harbin 150040, China

$\dagger$ These two authors contributed equally to this work.

* Author to whom correspondence should be addressed; E-Mail: hxkuang@hotmail.com; Tel.: +86-45182193001; Fax: +86-45182110803.

Received: 15 April 2011; in revised form: 28 April 2011 / Accepted: 29 April 2011 /

Published: 9 May 2011

\begin{abstract}
Chemical investigation of the ethanol extract of the root barks of Sambucus williamsii Hance collected in the Heilongjiang province of China resulted in the isolation of two new iridoid glycosides, williamsoside A (1) and williamsoside B (2). Their structures were elucidated on the basis of extensive spectroscopic analysis (1D, 2D-NMR and HRESIMS) and chemical studies. Iridoid glycosides have for a long time been considered as characteristic ingredients of $S$. williamsii. However, the presence of iridoid glycosides with apiofuranosyl moieties in $S$. williamsii is reported for the first time in this study.
\end{abstract}

Keywords: Sambucus williamsii Hance; root barks; iridoid glycosides

\section{Introduction}

Sambucus williamsii Hance, a tree widely distributed in China, belongs to the family Adoxaceae [1]. S. williamsii is also called in Chinese "Jie-gu-mu", "Da-jie-gu-dan", "Gong-lao-dao", etc. [2]. The root bark of this plant is a folk medicine with a long history of use in China for the treatment of fractures and osteoporosis [2]. Phytochemical studies showed that triterpenoids, flavonoids, lignans and the iridoid morroniside are major constituents of S. williamsii [3]. In our present work, investigation of its ethanol extract led to the isolation of two new iridoid glycosides. In this paper, we present the isolation 
and structural characterization of the two new iridoid glycosides on the basis of the interpretation of spectral data, including 1D, 2D NMR and HRESIMS data.

\section{Results and Discussion}

Compound 1 was obtained as a white amorphous powder and showed positive results for the Molisch reagent, which was considered to be indicative of an iridoid glycoside. Its molecular formula was established as $\mathrm{C}_{22} \mathrm{H}_{34} \mathrm{O}_{13}$ by the positive HRESIMS data, indicating six degrees of unsaturation.

The ${ }^{1} \mathrm{H}-\mathrm{NMR}$ spectrum of $\mathbf{1}$ (Table 1) showed the two characteristic signals of the common iridoid compounds, namely a proton at $\delta 5.11(1 \mathrm{H}, \mathrm{d}, J=6.2 \mathrm{~Hz})$ and a singlet at $\delta 7.41(1 \mathrm{H})$ corresponding to the $\mathrm{C}-1$ and C-3 protons, respectively. In addition, the signals at $\delta 3.68(3 \mathrm{H}, \mathrm{s})$ and $1.09(3 \mathrm{H}, \mathrm{d}, J=6.7 \mathrm{~Hz})$ were attributed to Me-12 and Me-10, respectively. The typical downfield signals at $\delta 4.64(1 \mathrm{H}, \mathrm{d}, J=7.9 \mathrm{~Hz})$, $4.99(1 \mathrm{H}, \mathrm{d}, J=2.3 \mathrm{~Hz})$ were assigned to the anomeric H-atom of the $\beta$-glucopyranosyl and $\alpha$-apiofuranosyl moieties according to their coupling constants and splitting patterns [4].

Table 1. ${ }^{1} \mathrm{H}$ and ${ }^{13} \mathrm{C}-\mathrm{NMR}$ data of 1 and 2 in $\mathrm{CD}_{3} \mathrm{OD}$ at $400 \mathrm{MHz}$ and $100 \mathrm{MHz}, J$ in $\mathrm{Hz}$.

\begin{tabular}{|c|c|c|c|c|}
\hline \multirow[t]{2}{*}{ No. } & \multicolumn{2}{|l|}{1} & \multicolumn{2}{|l|}{2} \\
\hline & $\delta_{H}$ & $\boldsymbol{\delta}_{\mathrm{C}}$ & $\delta_{H}$ & $\delta_{\mathrm{C}}$ \\
\hline 1 & $5.11(1 \mathrm{H}, \mathrm{d}, J=6.2)$ & 98.2 & $5.15(1 \mathrm{H}, \mathrm{d}, J=5.5)$ & 98.2 \\
\hline 3 & $7.41(1 \mathrm{H}, \mathrm{s})$ & 152.8 & $7.39(1 \mathrm{H}, \mathrm{d}, J=1.2)$ & 152.3 \\
\hline 4 & & 112.8 & & 113.8 \\
\hline 5 & $2.87(1 \mathrm{H}, \mathrm{dd}, J=7.8,15.7)$ & 35.5 & $3.11(1 \mathrm{H}, \mathrm{dd}, J=7.9,16.2)$ & 32.4 \\
\hline 6 & $2.20(1 \mathrm{H}, \mathrm{m}), 1.35(1 \mathrm{H}, \mathrm{m})$ & 33.6 & $1.60(1 \mathrm{H}, \mathrm{m}), 2.23(1 \mathrm{H}, \mathrm{m})$ & 42.8 \\
\hline 7 & $1.90(1 \mathrm{H}, \mathrm{m}), 1.89(1 \mathrm{H}, \mathrm{m})$ & 34.1 & $4.05(1 \mathrm{H}, \mathrm{dd}, J=4.4,4.0)$ & 75.0 \\
\hline 8 & $1.99(1 \mathrm{H}, \mathrm{q}, J=6.9,7.3)$ & 36.6 & $1.89(1 \mathrm{H}, \mathrm{m})$ & 42.4 \\
\hline 9 & $1.73(1 \mathrm{H}, \mathrm{m})$ & 48.4 & $1.99(1 \mathrm{H}, \mathrm{dt}, J=3.8,5.0)$ & 46.5 \\
\hline 10 & $1.09(3 \mathrm{H}, \mathrm{d}, J=6.7)$ & 21.0 & $1.10(3 \mathrm{H}, \mathrm{d}, J=6.8)$ & 13.7 \\
\hline 11 & & 169.7 & & 169.5 \\
\hline 12 & $3.68(3 \mathrm{H}, \mathrm{s})$ & 51.7 & $3.68(3 \mathrm{H}, \mathrm{s})$ & 51.6 \\
\hline 1 ' & $4.64(1 \mathrm{H}, \mathrm{d}, J=7.9)$ & 100.4 & $4.62(1 \mathrm{H}, \mathrm{d}, J=7.9)$ & 100.3 \\
\hline $2^{\prime}$ & $3.19(1 \mathrm{H}, \mathrm{m})$ & 74.7 & $3.19(1 \mathrm{H}, \mathrm{m})$ & 74.7 \\
\hline 3 ' & $3.35(1 \mathrm{H}, \mathrm{m})$ & 77.9 & $3.34(1 \mathrm{H}, \mathrm{m})$ & 77.9 \\
\hline 4 ' & $3.29(1 \mathrm{H}, \mathrm{m})$ & 71.5 & $3.26(1 \mathrm{H}, \mathrm{m})$ & 71.6 \\
\hline 5 & $3.42(1 \mathrm{H}, \mathrm{m})$ & 77.2 & $3.42(1 \mathrm{H}, \mathrm{m})$ & 77.2 \\
\hline $6^{\prime}$ & $3.68(1 \mathrm{H}, \mathrm{m}), 3.97(1 \mathrm{H}, \mathrm{m})$ & 68.4 & $3.62(1 \mathrm{H}, \mathrm{m}), 3.98(1 \mathrm{H}, \mathrm{m})$ & 68.5 \\
\hline $1 ”$ & $4.99(1 \mathrm{H}, \mathrm{d}, J=2.3)$ & 110.9 & $5.00(1 \mathrm{H}, \mathrm{d}, J=2.4)$ & 110.9 \\
\hline $2 ”$ & $3.88(1 \mathrm{H}, \mathrm{m})$ & 77.9 & $3.88(1 \mathrm{H}, \mathrm{m})$ & 77.9 \\
\hline $3 "$ & & 80.5 & & 80.5 \\
\hline \multirow[t]{2}{*}{$4 "$} & $3.95(1 \mathrm{H}, \mathrm{dd}, J=9.6)$ & 75.0 & $3.75(1 \mathrm{H}, \mathrm{dd}, J=9.6)$ & 75.0 \\
\hline & $3.75(1 \mathrm{H}, \mathrm{dd}, J=9.6)$ & & $3.94(1 \mathrm{H}, \mathrm{dd}, J=9.6)$ & \\
\hline $5 "$ & $3.55(1 \mathrm{H}, \mathrm{s})$ & 65.6 & $3.55(2 \mathrm{H}, \mathrm{s})$ & 65.5 \\
\hline
\end{tabular}


The ${ }^{13} \mathrm{C}$-NMR spectrum of $\mathbf{1}$ (Table 1) showed resonances for $22 \mathrm{C}$-atoms, including two quaternary carbons $(\delta 112.8,169.7)$, five methines $(\delta 98.2,152.8,35.5,36.6,48.4)$, two methylenes $(\delta 33.6,34.1)$, and two methyls $(\delta 21.0,51.7)$ belonging to the aglycone moiety, a glucopyranosyl group $(\delta 100.4,74.7,77.9,71.5,77.2,68.4)$, and an apiofuranosyl group $(\delta 110.9,77.9,80.5,75.0$, 65.6). C-1 that was connected with $\mathrm{C}-3$ through an oxygen atom on the basis of the chemical shifts of C-1 $(\delta 98.2)$ and C-3 ( $\delta$ 152.8), which was also confirmed by the HMBC correlations from H-3/C-1 and $\mathrm{H}-1 / \mathrm{C}-3$. The HMBC spectrum was used to elucidate the connection of different structural fragments, as well as to confirm the above assignments. In this spectrum, other key long-range correlations were observed between Me-10/C-7, C-8 and C-9, and between Me-12/C-11 (Figure 1). The connection positions of the glucopyranosyl and apiofuranosyl groups in $\mathbf{1}$ were established unambiguously by a HMBC experiment in which long-range correlations between H-1'/C-1, H-1/C-1', H-1'/C-6', and H-6'/C-1"'.

Figure 1. Key HMBC and NOESY correlations of $\mathbf{1 .}$
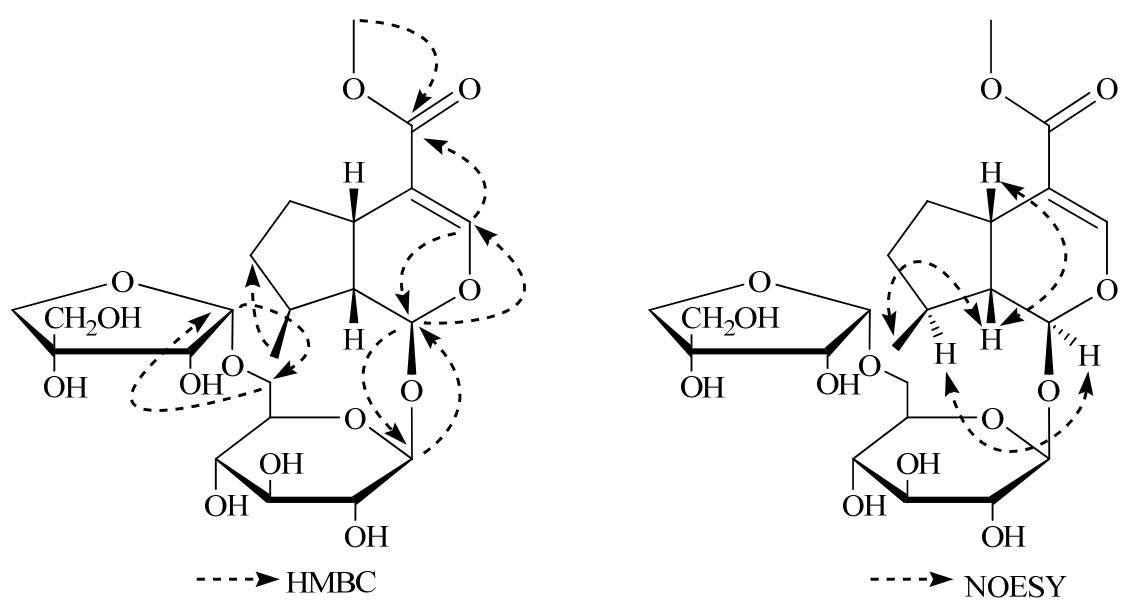

Since the stereochemistry of the three asymmetric centers (C-1, C-5, and C-9) was the same in practically all iridoids identified hitherto [5,6], the C-1 oxygen atom, H-5 and H-9 were assigned the $\beta$-orientation in the iridoid skeleton. The stereo configuration of $\mathrm{Me}-10$ was determined as a $\beta$-orientation on the basis of the key NOESY correlations between Me-10/H-9, H-9/H-5, and H-8/H-1 (Figure 2). Thus, the structure of 1 was identified to be 6'-apiosyldeoxyloganin, with the structure shown in Figure 2, and it was named williamsoside A.

Figure 2. Structures of 1 and 2.

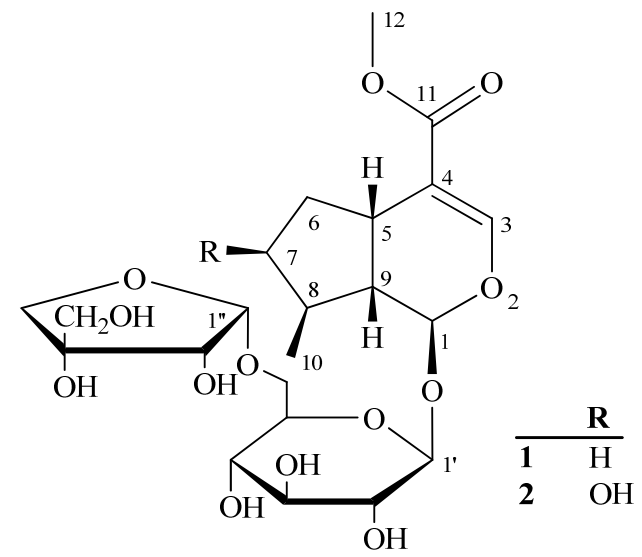


Compound 2 was obtained as a white amorphous powder and showed positive results for the Molisch reagent, which was also considered indicative of another iridoid glycoside. Its molecular formula was established as $\mathrm{C}_{22} \mathrm{H}_{34} \mathrm{O}_{14}$ by the positive HRESIMS, indicating six degrees of unsaturation. The ${ }^{1} \mathrm{H}-\mathrm{NMR}$ spectrum of $\mathbf{2}$ showed distinct resemblance to that of $\mathbf{1}$. The only notable difference was the change in the H-7 signal, which appeared as a double doublet at $\delta 4.05(1 \mathrm{H}, \mathrm{dd}, J=4.4$, $4.0 \mathrm{~Hz}$ ), indicating that $\mathrm{C}-7$ was substituted by a hydroxyl group. The ${ }^{13} \mathrm{C}-\mathrm{NMR}$ (DEPT) spectrum showed an additional downfield $\mathrm{C}$-atom signal at $\delta \mathrm{C} 75.0$ in 2, which was affirmatively assigned to the C-7 carbon. The stereo configuration of the hydroxyl group at C-7 and methyl group at C-8 was determined to be the $\beta$-orientation on the basis of the obvious NOESY correlations between $\mathrm{H}-7 / \mathrm{H}-8$, $\mathrm{H}-8 / \mathrm{H}-1$, Me-10/H-9, and H-9/H-5. On the basis of above data, the structure of 2 was identified to be as shown in Figure 2, and it was named williamsoside B.

\section{Experimental}

\subsection{General}

IR spectra were recorded on a Shimadzu FTIR-8400S spectrometer. NMR spectra were recorded on a Bruker DPX $400 \mathrm{NMR}$ instrument (at $400 \mathrm{MHz}$ for ${ }^{1} \mathrm{H}-\mathrm{NMR}$ and $100 \mathrm{MHz}$ for ${ }^{13} \mathrm{C}-\mathrm{NMR}$ ). Chemical shifts are given as $\delta$ values with reference to tetramethylsilane (TMS) used as internal standard, and coupling constants are given in Hz. HRESIMS were carried out on Waters Xevo QTOF mass spectrometer. Preparative HPLC (Waters, Delta 600-2487) was performed on a Hypersil-ODS II (10 m, $20 \times 300 \mathrm{~mm}$, Yilite, Dalian, China).

\subsection{Plant Material}

The root barks of $S$. williamsii were collected in August 2008 from the Fangzheng district, Heilongjiang Province, China, and identified by the author Zhen-Yue Wang. A voucher specimen (20080079) has been deposited at Heilongjiang University of Chinese Medicine, Harbin, China.

\subsection{Extraction and Isolation}

The dried root barks $(5.0 \mathrm{~kg})$ of $S$. williamsii were extracted with $95 \% \mathrm{EtOH}$ under reflux $(2 \times 10 \mathrm{~L})$ for $2 \mathrm{~h}$ (each time), and the combined soln. was filtered and concentrated under vacuum to an oily residue, which was suspended in $\mathrm{H}_{2} \mathrm{O}$. The suspension was passed through AB-8 crosslinked polystyrene, and sequentially eluted with $\mathrm{H}_{2} \mathrm{O}, 50 \% \mathrm{EtOH}$, and $95 \% \mathrm{EtOH}$, respectively. The 50\% EtOH elution fraction was concentrated under vacuum to yield a residue $(52.0 \mathrm{~g})$, which was subjected to silica gel column and eluted successively with $\mathrm{CHCl}_{3} / \mathrm{MeOH}(15: 1 \rightarrow 1: 1)$ to give 10 fractions (Fraction 1-10). Fraction 7 (5 g) was further separated by ODS column to afford 9 sub-fractions $\mathrm{A}_{1}-\mathrm{A}_{9}$. The sub-fraction $A_{9}$ was subjected to preparative HPLC (Hypersil-ODS $\Pi$ column) eluted with $\mathrm{MeOH} / \mathrm{H}_{2} \mathrm{O}(2: 3)$ to afford compounds $1(28 \mathrm{mg})$ and 2 (49 $\left.\mathrm{mg}\right)$.

Williamsoside $A(\mathbf{1})$ : White amorphous powder, $[\alpha]_{\mathrm{D}}^{25}=-27.0(\mathrm{c}=0.1, \mathrm{MeOH}) . \mathrm{IR}(\mathrm{KBr}): v=3303$, 2945, 2831, 1448, 1417, 1114, 1035, $659 \mathrm{~cm}^{-1}$. HRESIMS (positive): $\mathrm{m} / z=507.2057$ (calc. for $\mathrm{C}_{22} \mathrm{H}_{35} \mathrm{O}_{13}, 507.2028,[\mathrm{M}+\mathrm{H}]^{+}$), 524.2352 (calc. for $\mathrm{C}_{22} \mathrm{H}_{38} \mathrm{NO}_{13}, 524.2343,\left[\mathrm{M}+\mathrm{NH}_{4}\right]^{+}$), 529.1880 
(calc. for $\mathrm{C}_{22} \mathrm{H}_{34} \mathrm{NaO}_{13}, 529.1897,[\mathrm{M}+\mathrm{Na}]^{+}$) and 545.1628 (calc. for $\mathrm{C}_{22} \mathrm{H}_{34} \mathrm{KO}_{13}, 545.1636,[\mathrm{M}+\mathrm{K}]^{+}$). ${ }^{1} \mathrm{H}$ and ${ }^{13} \mathrm{C}-\mathrm{NMR}$ : see Table 1 .

Williamsoside $B$ (2): White amorphous powder, $[\alpha]_{\mathrm{D}}^{25}=-16.0(\mathrm{c}=0.1, \mathrm{MeOH}) . \mathrm{IR}(\mathrm{KBr}): v=3312$, 2945, 2833, 1447, 1419, 1113, 1035, $660 \mathrm{~cm}^{-1}$. HRESIMS (positive): $\mathrm{m} / z=523.2002$ (calc. for $\mathrm{C}_{22} \mathrm{H}_{35} \mathrm{O}_{14}, 523.2027,[\mathrm{M}+\mathrm{H}]^{+}$), 540.2271 (calc. for $\mathrm{C}_{22} \mathrm{H}_{38} \mathrm{NO}_{14}, 540.2292,\left[\mathrm{M}+\mathrm{NH}_{4}\right]^{+}$), and 545.1849 (calc. for $\mathrm{C}_{22} \mathrm{H}_{34} \mathrm{NaO}_{14}, 545.1846,[\mathrm{M}+\mathrm{Na}]{ }^{+}$). ${ }^{1} \mathrm{H}$ and ${ }^{13} \mathrm{C}-\mathrm{NMR}$ : see Table 1.

Acid Hydrolysis of $\mathbf{1}$ and 2. To a solution of 1 and 2 (each, $250 \mu \mathrm{g}$ ) in $\mathrm{MeOH}(1 \mathrm{~mL})$ was added 5\% $\mathrm{H}_{2} \mathrm{SO}_{4}(1 \mathrm{~mL})$ and the mixture was refluxed for $8 \mathrm{~h}$. The reaction mixture was then neutralized with saturated sodium carbonate and extracted with ethyl acetate (EtOAc, $2 \times 5 \mathrm{~mL}$ ) to give an aqueous fraction containing sugars and an EtOAc fraction containing the aglycone part. The aqueous phase was concentrated and compared with standard sugars using the TLC eluent systems EtOAc/ $n$-butanol/water (2:7:1) and $\mathrm{CH}_{2} \mathrm{Cl}_{2} / \mathrm{MeOH} /$ water (10:6:1) [7-9]; the two sugars were thus identified as apiose and glucose.

\section{Conclusions}

Iridoid glycosides represent a large group of cyclopentano[c]pyran monoterpenoids which have been reported to be associated with diverse biological activities including choleretic, purgative, liver protective, vasoconstrictive, antimicrobial, analgesic, antitumor, sedative and anti-inflammatory properties [10]. As a part of our chemical investigation on $S$. williamsii, we have isolated two new iridoid glycosides containing a 6'-apiofuranosyl moiety. Their structures were established on the basis of spectroscopic evidence. This is the first time iridoid glycosides with apiofuranosyl moieties have been reported in this species.

\section{Acknowledgements}

We would like to acknowledge the financial support from the State Key Creative New Drug Project of 11th Five-year Plan of China (2009ZX09103-383).

\section{References and Notes}

1. Tropicos. Missouri Botanical Garden. Available online: http://www.tropicos.org/ NameSearch.aspx?name= Sambucus/ (accessed on 18 April 2011).

2. Han, H.; Yan, Y.Y.; Kuang, H.X.; Dong, P.L. Advances in research of Sambucus williamsii hance. Inform. Trad. Chin. Med. 2008, 25, 14-16.

3. Ouyang, F.; Liu, Y.; Li, R.; Li, L.; Wang, N.L.; Yao, X.S. Five lignans and an iridoid from Sambucus williamsii. Chin. J. Nat. Med. 2011, 9, 26-29.

4. Garcia, J.; Chulia, A.J. Loganin and New iridoid glucosides in Gentiana pedicellata [J]. Planta Med. 1986, 52, 327-329.

5. Zapesochnaya, G.G.; Kurkin, V.A.; Pervykh, L.N.; Karasartov, B.S. Velpetin-A new iridoid glycoside from Nepeta velutina. Khim. Prir. Soedin. 1991, 6, 777-781.

6. Feng, C.L.; Gong, M.F.; Zeng, Y.B.; Dai, H.F.; Mei, W.L. Scyphiphin C, a New Iridoid from Scyphiphora hydrophyllacea. Molecules 2010, 15, 2473-2477. 
7. Bedir, E.; Toyang, N.J.; Khan, I.A.; Walker, L.A.; Clark, A.M. A new dammarane type triterpene glycoside from Polyscias fulva. J. Nat. Prod. 2001, 64, 95-97.

8. Chaturvedula, V.S.P.; Schilling, J.K.; Miller, J.S.; Andriantsiferana, R.; Rasamison, V.E.; Kingston, D.G.I. New cytotoxic oleanane saponis from the infructescences of Polyscias amplifolia from the Madagascar rainforest. Planta Med. 2003, 69, 440-444.

9. Huan, V.D.; Yamamura, S.; Ohtani, K.; Kasai, R.; Yamasaki, K.; Nham, N.T. Oleanane saponins from Polyscias fructicosa. Phytochemistry 1998, 47, 451-457.

10. Ling, S.K.; Tanaka, T.; Kouno, T. Effects of iridoids on lipoxygenase and hyaluronidase activities and their activation by $\beta$-glucosidase in the presence of amino acids. Biol. Pharm. Bull. 2003, 26, 352-356.

Sample Availability: Samples of williamsosides A and B are available from the authors.

(C) 2011 by the authors; licensee MDPI, Basel, Switzerland. This article is an open access article distributed under the terms and conditions of the Creative Commons Attribution license (http://creativecommons.org/licenses/by/3.0/). 